\title{
Letter to the Editor Regarding Anterior Lumbar Interbody Fusion With Cement Augmentation Without Posterior Fixation to Treat Isthmic Spondylolisthesis in an Osteopenic Patient-A Surgical Technique, by Cyriac et al.
}

Dear editor,

I read this paper with deep interest; I appreciate the author's work on this topic, although I have some comments about this paper.

The authors present and describe a case with spondylolisthesis at the lumbosacral junction treated with ALIF complemented with PMMA in a patient with scoliosis and osteopenia. ${ }^{1}$

In the presented case, the authors do not mention that this is not an L5-S1 level but an L5-transitional vertebra; a rudimentary disc is observed below the treated level, and I believe that this is not only a terminological issue.

First, the theoretical S1 endplate is actually the L5 endplate; is there any difference in terms of endplate resistance between both? This is probably a very difficult question but should be mentioned as a possibility.

Second, I believe that this is not an isthmic spondylolisthesis; to my consideration, this could be a degenerative spondylolisthesis, and therefore it is more stable than isthmic spondylolisthesis, and that is a possible reason to achieve better stability.

I would like to see a CT scan or MRI to better observe the pars defect, which is difficult to note probably due to the facet joint arthritis and scoliosis in this case.

Regarding the postoperative management, the authors mentioned the use of alendronate postoperatively during 8 weeks; why did the authors not include alendronate in the preoperative setting? Endplate subsidence can present in the short postoperative period, so it is important to decrease this phenomenon as soon as possible, especially considering the clinical results secondary to a sacral fracture, which can lead to symptom recurrence and the need for reoperation. ${ }^{2}$

Another question regarding the postoperative management is the use of an external orthotic device, such as a TLSO; has there been any recommendation in the postoperative setting to decrease the risk of subsidence or fracture?

The authors also mentioned that posterior fixation was undesirable due to the presence of L4-L5 lateral listhesis and scoliosis; my concern is the following: There is an important degeneration above the level treated; how can the authors be sure that this is not another source of pain? And, after that, if the level below a degenerative segment with lateral listhesis is fixed, it is probably that the patient will require a further surgical treatment in the short or mid term; this degenerative level acts as an adjacent segment disease and will suffer more stress load due to the fusion.

Did the authors consider this possibility?

Despite my concerns, the authors have provided an alternative treatment in a difficult case with a systemic problem (osteopenia/osteoporosis), which makes any fusion technique more challenging. I am looking forward to seeing more cases like this.

\section{REFERENCES}

1. Cyriac M, Kyhos J, Iweala U, et al. Anterior lumbar interbody fusion with cement augmentation without posterior fixation to treat isthmic spondylolisthesis in an osteopenic patienta surgical technique. Int J Spine Surg. 2018;12(3):322-327.

2. Lastfogel JF, Altstadt TJ, Rodgers RB, Horn EM. Sacral fractures following stand-alone L5-S1 anterior lumbar interbody fusion for isthmic spondylolisthesis. J Neurosurg Spine. 2010;13(2):288-293.

Gaston Camino Willhuber gaston.camino@hospitalitaliano.org.ar Hospital Italiano de Buenos Aires, Institute of Orthopedics "Carlos E. Ottolenghi," Orthopaedic and Traumatology Department, Buenos Aires, Argentina

Published 31 August 2019

This manuscript is generously published free of charge by ISASS, the International Society for the Advancement of Spine Surgery. Copyright (C) 2019 ISASS. To see more or order reprints or permissions, see http://ijssurgery.com. 